\title{
A high fat diet in CF-1 mice: An experimental model for metabolic syndrome
}

\author{
R. MOORE-CARRASCO ${ }^{1}$, C. ARANGUEZ-ARELLANO ${ }^{1}$, I. RAZMILIC ${ }^{2}$, L. TOLOZA ${ }^{1}$, \\ E. MORALES ${ }^{3}$, J.M. ARGILES ${ }^{4}$ and I. PALOMO ${ }^{1}$
}

\begin{abstract}
${ }^{1}$ Programa de Investigación en Factores de Riesgo de Enfermedad Cardiovascular, Departamento de Bioquímica Clínica e Inmunohematología, ${ }^{2}$ Instituto de Química y Recursos Naturales, Universidad de Talca; ${ }^{3}$ Escuela de Medicina,

Universidad Católica del Maule, Talca, Chile; ${ }^{4}$ Departamento de Bioquímica y Biología Molecular,

Facultad de Biología, Universidad de Barcelona, Barcelona, Spain
\end{abstract}

Received December 15, 2007; Accepted January 24, 2008

\begin{abstract}
Cardiovascular diseases account for the majority of deaths worldwide. Many of their risk factors have been identified but, for their continued study, research centering on new murine models is of interest. In this study, a high fat diet (HFD) and a normal diet (ND) (25 and 4.4\% fat, respectively) were tested over a 40-day period to induce the same metabolic alterations in CF-1 mice in two separate experiments. The parameters measured for these effects corresponded to the weight of ingested food and water, to the weight of the mice and their selected organs (adipose tissue, gastrocnemius, liver and heart), to their biochemical profile (glycemia, blood uric nitrogen, uric acid, triglycerides, cholesterol, proteins and albumin) and to the percentage of fat in their livers. The biochemical profile of the CF-1 mice fed a diet high in fat but balanced in proteins $(16.9 \%)$ showed statistically significant increases in glycemia, cholesterol and triglyceride levels. A statistically significant increase in the weight of adipose tissue was also observed. No statistically significant differences were observed in the muscular mass of either of the groups of mice, but a high percentage of fat was found in the liver. The results lead to the conclusion that CF-1 mice fed a HFD develop metabolic alterations that correspond to an equivalent metabolic syndrome. This is important in the evaluation of the effects of various interventions, such as food, exercise and molecules, on metabolic alterations in mice induced by the intake of a HFD.
\end{abstract}

\section{Introduction}

Cardiovascular diseases (CVDs) are the main cause of death worldwide (1). Several traditional CVD risk factors, such as

Correspondence to: Dr Rodrigo Moore-Carrasco, Department of Clinical Biochemistry and Inmunohematology, Faculty of Health Sciences, University of Talca, P.O. Box 747, Talca, Chile

E-mail:rmoore@utalca.cl

Key words: cardiovascular risk factors, high fat diet, $\mathrm{CF}-1$ mice arterial hypertension, tobacco addiction, hypercholesterolemia, hypertriglyceridemia and diabetes mellitus, have been identified $(2,3)$. The focus of the extensive research on CVD risk factors in the experimental field has been on the use of rodents, which allows an independent and easy study of the time period and the features under investigation. The most extensively used animals are rats, mice and hamsters. Diet is perhaps the most important factor in the development of research and the nutrition of experimental animals (4).

As the focus of our research is, in part, on traditional and emerging CVD risk factors and on strategies for the modification of these, it was important to have a murine model that exhibited these alterations, generated by a high fat diet (HFD). Our objective was therefore to establish a murine model that would develop the same metabolic alterations as those associated with CVD, such as hyperglycemia, hypercholesterolemia and hypertriglyceridemia.

\section{Materials and methods}

Two experiments were carried out over a period of 40 days. Each included a group of mice fed with a normal diet (ND) and a group fed a HFD. All mice were maintained under the same conditions. Experiments were conducted 6 months apart.

Animals and diets. Male CF-1 mice, 4 and 6 weeks old, (Instituto de Salud Pública, Santiago, Chile) were used in experiments 1 and 2, respectively. The animals were maintained at $22 \pm 2^{\circ} \mathrm{C}$ in a regular $12: 12 \mathrm{~h}$ light-dark cycle (light from 08.00 to $20.00 \mathrm{~h}$ ) and were administered food and water ad libitum, with intake measured daily. All animal manipulations were conducted in accordance with the Guidelines For the Use of Laboratory Animals of the University of Talca Bioethics Committee. The protocol was approved by the Universidad de Talca Institutional Animal Care and Use Committee following the recommendations of the Canadian Council on Animal Care (5).

At the end of the 40-day experimental period, mice were anaesthetized with an i.p. injection of a mixture of ketamine 10\% (Ketostop; Drug Pharma-Invetec, Santiago, Chile) and xylazine 2\% (Xylavet; Alfasan International B.V., Holland). Blood obtained from the aorta was used in order to determine 
Table I. Percentages of the components of the normal and high fat diets.

\begin{tabular}{lrrrr}
\hline & \multicolumn{2}{c}{ Experiment 1} & \multicolumn{2}{c}{ Experiment 2 } \\
\cline { 2 - 5 } & Normal diet & High fat diet & Normal diet & High fat diet \\
\hline Water (\%) & 6.25 & 5.82 & 6.90 & 6.80 \\
Lipids (\%) & 4.44 & 25.30 & 5.30 & 24.30 \\
Myristic acid (\%) & 4.98 & 1.70 & 5.10 & 1.20 \\
Palmitic acid (\%) & 47.28 & 27.01 & 48.6 & 29.30 \\
Linoleic acid (\%) & 15.00 & 28.01 & 15.80 & 27.06 \\
Oleic acid (\%) & 21.11 & 32.10 & 22.01 & 30.20 \\
Stearic acid (\%) & 8.19 & 8.91 & 8.68 & 12.14 \\
Protein (\%) & 20.80 & 16.92 & 20.10 & 18.60 \\
Carbohydrates (\%) & 57.31 & 42.56 & 55.70 & 4.90 \\
Inorganic components (\%) & 7.20 & 5.40 & 4.10 & 40.40 \\
Fibre (\%) & 4.00 & 4.00 & 5.90 \\
\hline
\end{tabular}

Only those fatty acids which presented a percentage $>1$ are listed.

serum biochemistry parameters. Anaesthetized mice were sacrificed by exsanguination. The liver, gastrocnemius, white adipose tissue and heart were excised and stored at $-80^{\circ} \mathrm{C}$ for later experiments.

In both experiments, the mice were fed the same chow diet for one week prior to the feeding of special diets. Following this acclimatization period, they were divided into two groups ( $\mathrm{n}=6$ and 8); one group was fed a ND (4,4\% fat) (Champion S.A., Santiago, Chile) and the other a HFD based on the ND and supplemented with cow fat and sunflower oil from a local supermarket (25\% fat). For component analysis, five pellets were selected at random from each diet and were pulverized. Then, the water, protein, carbohydrate, inorganic component and lipid content was measured according to the standardized Official Methods of Analysis of the Association of Official Analytical Chemists (6). Lipid content was dermined by the Soxleth method, protein by the Kjeldahl method, water by dehydration at high temperatures, and fiber by acid and base digestion and calcination. The lipid content of the fat fraction of the diet was determined by gas chromatography/mass spectrometry (Perkin Elmer Turbo Mass and Autosystem XL Gas Chromatograph). There were no significant differences between any of the components of the NDs or HFDs in experiments 1 and 2 (Table I). Elucidation patterns of the applied standards demonstrated that the ND consisted of a mixture of fatty acids with a predominance of palmitic acid. In contrast, the HFD consisted predominantly of the fatty acids of 16 atoms of saturated and 18 atoms of monounsaturated and diunsaturated carbons (Table I). The remaining fatty acids of the diets presented low and variable percentages.

Biochemicals. All reagents for the determination of uric acid, total cholesterol, HDL-cholesterol (HDL-c), triglycerides, blood uric nitrogen, glutamic pyruvic transaminase (GPT) and glutamic oxalacetic transaminase (GOT) were obtained from Roche S.A. (Santiago, Chile). Analyses were conducted using the Hitashi 717 (Japan).
Biochemical analyses were carried out in all of the mice, with the exception of those blood was impossible to extract prior to their sacrifice.

Statistical analysis. Statistical analysis of the data was performed using the Student's t-test (SPSS) (15).

\section{Results}

Food intake and body weight. During the acclimatization phase and at the start of the experimental period, there were no differences between the food intake and body weight of the mice. At the end of both experimental periods, no statistical difference was found between the food intake of the ND and HFD groups in experiment 1 (ND 5.4 \pm 4.4 , HFD 5.0 $\pm 3.3 \mathrm{~g} /$ day) or 2 (ND $6.8 \pm 0.8, \mathrm{HFD} 7.8 \pm 2.6 \mathrm{~g} /$ day); however, there was a difference in the body weight (final weight - initial weight) of the ND and HFD mice in experiments 1 (ND 14.1 $\pm 0.3 \mathrm{~g}$, HFD $16.5 \pm 0.6 \mathrm{~g}, \mathrm{p}<0.01$ ) and 2 (ND 8.6 $\pm 1.2 \mathrm{~g}, \mathrm{HFD} 11.2 \pm 2.5 \mathrm{~g}$, $\mathrm{p}=0.09)$.

At the end of both experiments, the epididymal fat pad weight of the mice fed a HFD was higher than in those fed a ND (Table II). No statistical differences in the gastrocnemius, liver or heart weight were observed in either group in either of the experiments (Table II).

Biochemical blood analysis. In both experiments, mice fed a HFD presented significant increases in serum levels of glucose, total cholesterol and triglycerides (Table III). The GPT and GOT, determined only in experiment 2, showed a significant increase in GOT activity in the HFD group (Table III).

Hepatic lipids. A significant percent increase in the hepatic lipid level of the mice fed a HFD in comparison with those fed a ND was observed in both experiments: experiment $1, \mathrm{ND}$ $(\mathrm{n}=3) 2.3 \pm 0.5 \%$, HFD $(\mathrm{n}=4) 4.2 \pm 0.2 \%, \mathrm{p}<0.001$; experiment 2 , ND $(n=6) 3.5 \pm 1.0 \%$, HFD $(n=5) 5.2 \pm 1.1 \%, p=0.02$. 
Table II. Weight of the organs and tissues of the mice fed a normal versus high fat diet.

\begin{tabular}{|c|c|c|c|c|c|c|}
\hline & \multicolumn{3}{|c|}{ Experiment 1} & \multicolumn{3}{|c|}{ Experiment 2} \\
\hline & $\begin{array}{l}\text { Normal diet } \\
\qquad(n=7)\end{array}$ & $\begin{array}{l}\text { High fat diet } \\
\qquad(\mathrm{n}=8)\end{array}$ & P-value & $\begin{array}{l}\text { Normal diet } \\
\qquad(n=6)\end{array}$ & $\begin{array}{l}\text { High fat diet } \\
\qquad(n=5)\end{array}$ & P-value \\
\hline \multicolumn{7}{|l|}{ Tissues } \\
\hline Epididymal fat pad (g) & $0.40 \pm 0.03$ & $0.90 \pm 0.09$ & $<0.001$ & $0.57 \pm 0.09$ & $1.31 \pm 0.32$ & $<0.050$ \\
\hline Gastrocnemius (g) & $0.90 \pm 0.04$ & $1.00 \pm 0.04$ & NS & $0.60 \pm 0.03$ & $0.60 \pm 0.02$ & NS \\
\hline \multicolumn{7}{|l|}{ Organs } \\
\hline Liver $(\mathrm{g})$ & $6.50 \pm 0.32$ & $5.90 \pm 0.24$ & NS & $5.91 \pm 0.19$ & $6.38 \pm 0.45$ & NS \\
\hline Heart (g) & $0.50 \pm 0.03$ & $0.50 \pm 0.02$ & NS & $0.53 \pm 0.04$ & $0.65 \pm 0.05$ & NS \\
\hline
\end{tabular}

NS, not significant.

Table III. Biochemical parameters of the mice fed a normal versus high fat diet.

\begin{tabular}{|c|c|c|c|c|c|c|}
\hline & \multicolumn{3}{|c|}{ Experiment 1} & \multicolumn{3}{|c|}{ Experiment 2} \\
\hline & $\begin{array}{l}\text { Normal diet } \\
\qquad(n=5)\end{array}$ & $\begin{array}{l}\text { High fat diet } \\
\qquad(\mathrm{n}=5)\end{array}$ & $\mathrm{P}=$ value & $\begin{array}{l}\text { Normal diet } \\
\qquad(n=6)\end{array}$ & $\begin{array}{l}\text { High fat diet } \\
\qquad(n=6)\end{array}$ & P-value \\
\hline $\begin{array}{l}\text { Glutamic oxalacetic } \\
\text { transaminase (UI/l) }\end{array}$ & ND & ND & - & $125.3 \pm 11.01$ & $524.5 \pm 169.30$ & $<0.05$ \\
\hline $\begin{array}{l}\text { Glutamic pyruvic } \\
\text { transaminase (UI/l) }\end{array}$ & ND & ND & - & $75.7 \pm 8.68$ & $419.1 \pm 221.59$ & NS \\
\hline Uric acid (mg/dl) & $6.3 \pm 2.29$ & $6.6 \pm 1.13$ & NS & ND & ND & - \\
\hline Blood uric nitrogen $(\mathrm{mg} / \mathrm{dl})$ & $21.8 \pm 4.08$ & $25.2 \pm 5.72$ & NS & $21.8 \pm 2.12$ & $24.2 \pm 3.62$ & NS \\
\hline Glycemia (mg/dl) & $316.8 \pm 13.43$ & $452.2 \pm 43.54$ & $<0.010$ & $304.1 \pm 12.02$ & $406.3 \pm 40.01$ & $<0.05$ \\
\hline Total cholesterol (mg/dl) & $89.0 \pm 7.94$ & $206.6 \pm 8.66$ & $<0.001$ & $108.9 \pm 10.55$ & $174.1 \pm 11.79$ & $<0.01$ \\
\hline HDL-cholesterol (mg/dl) & ND & ND & - & $115.4 \pm 9.68$ & $126.0 \pm 11.22$ & NS \\
\hline Triglycerides (mg/dl) & $79.7 \pm 15.19$ & $234.4 \pm 38.77$ & $<0.050$ & $128.9 \pm 17.07$ & $203.2 \pm 28.36$ & $<0.05$ \\
\hline
\end{tabular}

ND, not determined; NS, not significant.

\section{Discussion}

It is known that diabetes, dyslipidemia and arterial hypertension are classic cardiovascular risk factors (7-12). For the study of atherosclerosis, knockout mice are generally used for ApoE $(13,14)$ and the LDL receptor $(15)$. However, some murine models of metabolic syndrome have been described $(4,16,21)$. Our objective was to create a non-genetically modified murine model that presented the metabolic alterations, such as an increase in glycemia, cholesterol and triglycerides, observed with high frequency in the adult populations of both developed and developing countries.

High fat diet. The study of obesity and its effects on experimental animals, mainly rats and mice, has generated different diets, acheived by altering the types and concentrations of nutrients used $(4,16-18)$. One of the generated models is the
HFD $(4,16,17)$. In the present study, a $25 \%$ lipid diet was used, which consisted of a lower proportion of palmitic acid and a higher proportion of linoleic and oleic acids than the ND.

The percent composition of lipids in the diets used in this study was similar to those used by other researchers (18-20), though the diet differed from those commonly used (21-23). Some of the components used in its preparation were similar to those used in other studies, for example sunflower oil (24-26) and animal butter $(27,28)$. Palmitic acid, the main fatty acid present in diets, has been associated with the development of dyslipidemia and insulin resistance $(29,30)$. Other fatty acids present in diets are oleic and linoleic acid, which have been observed to improve insulin sensitivity in skeletal muscle, help reduce abdominal obesity and decrease dyslipidemia (31). Meanwhile, it has been reported that linoleic acid selectively encourages a pro-inflammatory environment in human endo- 
thelial cells (32), stimulating lipid peroxidation and decreasing levels of HDL-c (33).

Metabolic alterations. CF-1 mice fed a HFD, in addition to presenting an increase in epididymal adipose tissue, presented a significant increase in glycemia, total cholesterol and triglyceridea, all of which are CVD risk factors.

Adipose and hepatic tissue. Along with the increase in fat in the liver, we found that the GPT and GOT enzymes, which are markers of hepatic steatosis, were increased. Studies, like the one developed by Axen et al, show that the consumption of a HFD can result in an increase in visceral adipose tissue, as well as in an increase in lipid content at the hepatic level (24).

Hyperglycemia. Wilkes et al (25) demonstrated, using Sprague Dawley rats, that the consumption of a diet rich in fat based on sunflower oil increased the basal uptake of glucose, but decreased the capitation of glucose stimulated by insulin in the skeletal muscle. This might be explained by the alteration caused by this type of diet in the composition and/or functionality of the GLUT-4 glucose transporter at this level (34). On the other hand, it has been demonstrated that the presence of unsaturated fatty acids in diets damages insulin secretion, which is not the case with fatty acids that present a high insulinotropic potential (27). As sunflower oil was one of the ingredients used in the current study's HFD, it is possible that the above-mentioned finding explains, at least in part, the hyperglycemia observed in our experiments.

Dislipidemia. Lin et al (35), working with Wistar male rats and golden Syrian hamsters, found that a diet high in cholesterol and associated with n-3 polyunsaturated fatty acids (PUFA), but not with n-6 PUFA, increased the concentration of very low density lipoproteins, hypertriglyceridemia and hypercholesterolemia. The HFD administered in the current study consisted of high quantities of linoleic acid (n-3 PUFA). This might explain the hypertriglyceridemia and hypercholesterolemia observed. Other authors, studying the effects on Bio $F_{1} B$ hamsters of fish oil-supplemented diets with or without cholesterol, found in the first case a higher frequency of dyslipidemia (28).

One of the lipid parameters of major recent relevance is HDL-c (36). Normal levels are associated with reduced risk in cardiovascular patients with MS (37). However, human and mouse lipoparticle levels are not comparable. In humans, LDL-c is predominant; in mice, HDL-c predominates (38). Perhaps this disparity explains why no differences have been found in our studies between animals fed with a HFD and a ND.

In summary, CF- 1 mice fed a HFD for 40 days exhibited increased visceral fat, glucose, cholesterol, triglyceride, transaminase and liver lipid content. We did not measure arterial pressure or insulinemia, yet it is probable that the $\mathrm{CF}-1$ murine model closely resembles metabolic syndrome in humans. This model, with the alterations described above, will allow for future study of the effects of various manipulations, such as food (e.g. apples, which have provided some interesting preliminary results), exercise, extracts or molecules, with eventual pharmacologic activity.

\section{Acknowledgements}

This study was supported by the Research Department (VAC 600377) and Research Program of Cardiovascular Disease Risk Factors (PIFRECV), Universidad de Talca, Chile.

\section{References}

1. World Health Organization: Informe sobre la salud en el mundo. Technical Report Series ISBN 924356207 X. WHO, Geneva, 2002.

2. Eaton CB: Traditional and emerging risk factors for cardiovascular disease. Prim Care 32: 963-976, 2005.

3. Palomo I, Icaza G, Mujica V, Nuñez L, Leiva E, Vásquez M, Alarcón M and Moyano E: Prevalencia de factores de riesgo cardiovascular clásicos en población adulta de Talca, Chile, 2005. Rev Méd Chile 135: 904-912, 2007.

4. Buettner R, Schölmerich J and Bollheimer LC: High-fat diets: modeling the metabolic disorders of human obesity in rodents. Obesity 15: 798-808, 2007.

5. Olfert ED, Cross BM and McWilliam AA (eds): Guide to the Care and Use of Experimental Animals. Vol. 1. Canadian Council on Animal Care, Ottawa, ON, pp1-213, 1993.

6. Helrich K (ed): Official Method of Analysis of the A.O.A.C. 15th edition. Association of Official Analytical Chemists, Arlington, VA, 1990.

7. Scholze J, Lilienthal W and Bramlage P: Cardiometabolic high risk patients with abdominal obesity. Frequency and risk factor profile in primary care. MMW Fortschr Med 149: 103-110, 2007.

8. Wienbergen H, Gitt AK, Juenger C, Schiele R, Heer T, Towae F, Gohlke $\mathrm{H}$ and Senges J, for the MITRA PLUS study group: Impact of the body mass index on occurrence and outcome of acute STelevation myocardial infarction. Clin Res Cardiol: Oct. 19, 2007 (Epub ahead of print).

9. Livingston $\mathrm{EH}$, Chandalia $\mathrm{M}$ and Abate $\mathrm{N}$ : Do current body mass index criteria for obesity surgery reflect cardiovascular risk? Surg Obes Relat Dis 6: 577-585, 2007.

10. Farajian P, Renti E and Manios Y: Obesity indices in relation to cardiovascular disease risk factors among young adult female students. Br J Nutr 5: 1-7, 2007.

11. Haffner SM: Abdominal adiposity and cardiometabolic risk: Do we have all the answers? Am J Med 120: 10-16, 2007.

12. Okamura T: Cardiovascular risk clustering with obesity: a good target to reduce medical expenditures as a first step of high-risk approach in communities and worksites. Circ J 71: 1667, 2007.

13. Gonzalez-Navarro H, Burks DJ and Andres V: Murine models to investigate the influence of diabetic metabolism on the development of atherosclerosis and restenosis. Front Biosci 12: 4439-4455, 2007.

14. Castro C, Campistol JM, Barettino D and Andres V: Transcriptional profiling of early onset diet-induced athero-sclerosis in apolipoprotein E-deficient mice. Front Biosci 10: 1932-1945, 2005.

15. Mehta JL, Sanada N, Hu CP, et al: Deletion of LOX-1 reduces atherogenesis in LDLR knockout mice fed high cholesterol diet. Circ Res 100: 1634-1642, 2007.

16. Caluwaerts S, Lambin S, van Bree R, Peeters H, Vergote I and Verhaeghe J: Diet-induced obesity in gravid rats engenders early hyperadiposity in the offspring. Metabolism 56: 1431-1438, 2007.

17. Young GS and Kirkland JB: Rat models of caloric intake and activity: relationships to animal physiology and human health. Appl Physiol Nutr Metab 32: 161-176, 2007.

18. Russell JC and Proctor SD: Small animal models of cardiovascular disease: tools for the study of the roles of metabolic syndrome, dyslipidemia, and atherosclerosis. Cardiovasc Pathol 15: 318-330, 2006.

19. Roberts CK, Vaziri ND, Hui Lang K, et al: Reversibility of chronic experimental syndrome $\mathrm{X}$ by diet modification. Hypertension 37 : 1323-1328, 2001

20. Wang H, Storlien LH and Huang X-F: Effects of dietary fat types on body fatness, leptin, and ARC leptin receptor, NPY, and AgRP mRNA expression. Am J Physiol Endocrinol Metab 282: E1352-E1359, 2002.

21. Taouis M, Dagou C, Ster C, et al: N-3 polyunsaturated fatty acids prevent the defect of insulin receptor signaling in muscle. Am J Physiol Endocrinol Metab 282: E664-E671, 2002.

22. Youngren JF, Paik J and Barnard RJ: Impaired insulin-receptor autophosphorylation is an early defect in fat-fed, insulin-resistant rats. J Appl Physiol 91: 2240-2247, 2001. 
23. Hegarty BD, Cooney GJ, Kraegen EW, et al: Increased efficiency of fatty acid uptake contributes to lipid accumulation in skeletal muscle of high fat-fed insulin-resistant rats. Diabetes 51: 1477-1484, 2002.

24. Axen KV, Dikeakos A and Sclafani A: High dietary fat promotes syndrome X in nonobese rats. J Nutr 133: 244-249, 2003.

25. Wilkes JJ, Bonen A and Bell RC: A modified high-fat diet induces insulin resistance in rat skeletal muscle but not adipocytes. Am J Physiol 275: E679-E686, 1998.

26. Lavigne C, Tremblay F, Asselin G, et al: Prevention of skeletal muscle insulin resistance by dietary cod protein in high fat-fed rats. Am J Physiol Endocrinol Metab 281: E62-E71, 2001.

27. Dobbins RL, Szczepaniak LS, Myhill J, et al: The composition of dietary fat directly influences glucose-stimulated insulin secretion in rats. Diabetes 51: 1825-1833, 2002.

28. De Silva PP, Davis PJ and Kaur Cheema S: Hyperlipidaemic effect of fish oil on Bio $F_{1} B$ hamsters. Brit J Nutr 91: 341-349, 2004.

29. Grundy SM, Abate N and Chandalia M: Diet composition and the metabolic syndrome: What is the optimal fat intake? Am J Med 113: 25-29, 2002.

30. German JB and Dillard CJ: Saturated fats: What dietary intake? Am J Clin Nutr 80: 550-559, 2004.

31. Taylor CG and Zahradka P: Dietary conjugated linoleic acid and insulin sensitivity and resistance in rodent models. Am J Clin Nutr 79: 1164-1168, 2004.
32. Toborek M , Lee YW, Garrido R, et al: Unsaturated fatty acids selectively induce an inflammatory environment in human endothelial cells. Am J Clin Nutr 75: 119-125, 2002.

33. Risérus U, Basu S, Jovinge S, et al: Supplementation with conjugated linoleic acid causes isomer-dependent oxidative stress and elevated C-reactive protein A. Potential link to fatty acidinduced insulin resistance. Circulation 106: 1925-1929, 2002.

34. Hanssen PA, Han DH, Marshall BA, et al: A high fat diet impairs stimulation of glucose transport in muscle. Functional evaluation of potential mechanisms. J Biol Chem 273: 26157-26163, 1998.

35. Lin M-H, Lu S-H, Huang P-C, et al: A high-cholesterol, n-3 polyunsaturated fatty acid diet causes different responses in rats and hamsters. Ann Nutr Metab 49: 386-391, 2005.

36. Assmann G and Gotto AM Jr: HDL cholesterol and protective factors in atherosclerosis. Circulation 109: 8-14, 2004.

37. Cannon CP: High-density lipoprotein cholesterol and residual cardiometabolic risk in metabolic syndrome. Clin Cornerstone 8: 14-23, 2007.

38. Matsuzawa N, Takamura T, Kurita S, Misu H, Ota T, Ando H, Yokoyama M, Honda M, Zen Y, Nakanuma Y, Miyamoto K and Kaneko S: Lipid-induced oxidative stress causes steato-hepatitis in mice fed an atherogenic diet. Hepatology 46: 1392-1403, 2007. 